\title{
El estudio de las haciendas. Un balance historiográfico
}

\section{Por Catalina Ahumada Escobar}

\begin{abstract}
Resumen
El siguiente artículo presenta la revisión histórica de los estudios sobre las haciendas latinoamericanas para aproximarnos al estado de la cuestión y las diferentes formas de construcción del problema de investigación en el caso colombiano, particularmente sobre el estudio de las haciendas esclavistas, teniendo presente el caso del suroccidente colombiano.
\end{abstract}

Palabras claves: Haciendas, colonia, esclavitud, sistema patriarcal.

\section{Abstract}

This article presents a historical review of studies on Latin American haciendas to approach the research of the problem in the Colombian case, particularly in the study on the slave haciendas.

Key words: Haciendas, colony, slavery, patriarchal system.

Desde la década de 1930, en un contexto en que las ciencias sociales plantearon nuevos temas y problemas sobre la realidad a investigar, emergieron las primeras aproximaciones a las dinámicas socioeconómicas que evidenciaron cambios estructurales y algunas continuidades del orden colonial tradicional relacionados con la hacienda.

Para 1933 se publicó la obra del antropólogo Gilberto Freyre, 'Casa Grande y Senzala. Formación de la familia brasileña bajo el régimen de economía patriarcal'. El autor estudió la historia social brasileña a través de la "historia íntima" manifiesta en la rutina diaria en las haciendas y grandes plantaciones azucareras. Interpretó de esta forma, algunos aspectos de la formación de la familia brasileña dando cuenta de un proceso de mestizaje y un sistema cultural particular acentuando la diferencia entre raza y cultura, como avance en la visión de los estudios tradicionales de la época. Según Freyre, "La casagrande completada por la senzala representa todo un sistema económico, social y político. (...) En el estudio de su historia íntima se menosprecia todo lo que la historia política y militar nos presenta de arrebatador, por una casi rutina de vida, pero dentro de esta rutina es donde mejor se siente el carácter de un pueblo" (Freyre, 1933).

Los primeros estudios a partir de un trabajo empírico sobre la hacienda como complejo socioeconómico clave de la realidad social latinoamericana, se da inicio en la década de 1950 con los trabajos del historiador francés François

\footnotetext{
* Artículo de investigación científica tipo 3: de revisión. Según clasificación de Colciencias. Hace parte del proyecto de investigación: La Hacienda Coconuco. Aspectos sociales y culturales. $1770-1580$. Trabajo presentado para optar el título de Magíster en Sociología, Universidad del Valle, Facultad de Ciencias Sociales y Económicas, Departamento de Sociología, Maestría en Sociología, 2010.

*** Historiadora y Magíster en Sociología, Universidad del Valle. Profesora Universidad Autónoma de Occidente. E-mail: catalinaae@yahoo.com
} 
Chevalier sobre México y los antropólogos norteamericanos Eric Wolf y Sidney Mintz sobre Centro América y las Antillas. Trabajos que están inscritos en el interés que produce Latinoamérica sobre su estructura y dinámica económica vista desde la óptica de los investigadores de los países desarrollados, dinámica que se explicará más adelante.

El trabajo de Chevalier La formación de las grandes propiedades en México. Tierra y sociedad en los siglos XVI-XVII, publicado en 1952, evidencia una marcada influencia en su formación de la Escuela de los Anales y los trabajos de Marc Block sobre historia medieval. El historiador presenta la hacienda tradicional como un gran latifundio en la estructura semifeudal de las grandes propiedades que emergieron a partir del siglo XVI, caracterizada por su poca conexión con el exterior, que no generaba importantes rentas para sus propietarios pero que su valor obedecía principalmente al prestigio social generado por la posesión de la tierra en esa sociedad aristocrática.

En el siguiente año Wolf y Mintz publicaron su estudio Las haciendas y plantaciones en Mesoamérica y Las Antillas (1975) a partir de un trabajo de campo en Puerto Rico, Jamaica, México y un análisis de fuentes escritas de los siglos XIX y XX. Su objetivo principal fue considerar la hacienda y plantación como dos tipos de sistemas sociales a partir de la construcción de un modelo operacional, es decir la generalización de ciertas características propias de semejanza y distinción. Estos sistemas sociales fueron delimitados por sus dimensiones de capital, mercado, tierra, mano de obra, tecnología y las sanciones o castigos, aspectos que permiten observar los mecanismos sociales, psicológicos y económicos vinculados a la hacienda. En este sentido estos dos tipos de organización agraria fueron definidos de la siguiente manera:

\begin{abstract}
Hacienda será una propiedad agrícola operada por un terrateniente que dirige y una fuerza de trabajo que le está supeditada, organizada para aprovisionar un mercado de pequeña escala por medio de un capital pequeño, y donde los factores de la producción se emplean no sólo para la acumulación de capital sino también para sustentar las aspiraciones de status del propietario. Y la plantación, será una propiedad agrícola operada por propietarios dirigentes (por lo general organizados en sociedad mercantil) y una fuerza de trabajo que les está supeditada, organizada para aprovisionar un mercado a gran escala por medio de un capital abundante y donde los factores de producción se emplean principalmente para fomentar la acumulación de capital sin ninguna relación con las necesidades de los dueños (Wolf y Mintiz, 1975, p. 493).
\end{abstract}

Estos planteamientos fueron aprovechados en gran parte por investigaciones que en los en los siguientes años se interesaron en reconstruir el desarrollo de la sociedad rural latinoamericana, estudios que fueron publicados a partir de 1960. En esta tarea el balance realizado por el historiador sueco Magnus Morner en 1973, quien analiza los trabajos pioneros de Chevalier, Wolf y Mintz, así como, las investigaciones posteriores, evidencia los principales avances y limitaciones.

Morner llama la atención sobre todo en el uso generalizado y apresurado de la definición de los conceptos frente a la evidencia histórica. El autor motiva a la 
investigación futura al uso de fuentes que permitan la reconstrucción de la hacienda inscrita en dinámicas precisas a través del tiempo, para realizar aproximaciones más certeras sobre el origen, el trabajo, la producción, los mercados y la poca atención merecida a la hacienda como núcleo social.

En la década de 1970 hay una mayor proliferación de trabajos en torno a la hacienda, interés que se puede observar además en varios seminarios, coloquios y simposios que en torno al tema se realizaron. La publicación La Hacienda en América Latina. Su importancia histórica para la economía y la sociedad (Siebbermann, 1979), recopila las actas del coloquio interdisciplinar de San Gall (Suiza) en 1978. Un interesante balance realizado por especialistas en el tema quienes retoman las investigaciones y debates realizados sobre todo de los últimos diez años. De este encuentro académico en San Gall es importante señalar varios puntos.

Para comenzar es interesante observar que entre los doce de los ponentes solo uno es de nacionalidad latinoamericana, lo que evidencia un interés significativo de los investigadores no latinoamericanos sobre este tópico, que además se hace notorio en el estado de la cuestión para la fecha. A partir de este fenómeno que es tenido en cuenta en la dinámica central del debate, se advierte que en el pensamiento intelectual de las dos últimas décadas se había enfatizado en gran medida por indagar sobre aspectos responsables del estancamiento socioeconómico de esta parte del continente (Siebbermann, 1979, p. IX).

En esta discusión se examina precisamente la intervención de las ciencias sociales en la búsqueda de las causas del subdesarrollo de América Latina, relacionando la hacienda con la permanencia del gran latifundio improductivo y la preeminencia entonces de una reforma agraria. El historiador alemán Piestschmann nos dice que "de pronto tuvo gran auge esta discusión en los años 60, con la proliferación de las distintas teorías de la dependencia, derivadas del concepto original de la CEPAL (Comisión Económica para América Latina)" (1979, p. 39). La hacienda latinoamericana así, adquirió el papel protagónico en términos que giraban en torno a su percepción como institución feudal o semifeudal que importaba caracterizar.

El debate interdisciplinar de historiadores, sociólogos y economistas principalmente, logró en este encuentro algunos acuerdos sobre el estado de la cuestión así como desacuerdos, inquietudes e interrogantes por resolver frente a las diferentes perspectivas de análisis que se exponen a continuación. Si bien se señala que hasta ese momento algunos investigadores continuaron trabajando con una definición generalizada en un principio por Wolf y Mintz, las investigaciones recientes muestran que la hacienda "presenta en todos los aspectos tal variedad de matices y formas particulares que resulta muy difícil seguir hablando de ella como de un tipo determinado de explotación agraria de rasgos invariantes" (Piestschmann, 1979, p. 45).

Pero el debate profundizó aún más en la continuidad de ciertos estereotipos sobre el análisis de la hacienda. Por ejemplo en la persistencia por definirla como una gran propiedad ante una serie de trabajos que muestran 
precisamente la existencia de grandes y medianas propiedades y la coexistencia de otro tipo de propiedades fuera de las plantaciones y haciendas. Referente a su caracterización como posesión feudal o semifeudal, algunos autores distinguen la utilización de dichos términos fuera de contexto, siendo importante para otros, no el concepto en sí, sino la caracterización del sistema. En consenso se argumentó también, que es equívoco la idea de seguir pensando la hacienda como un mecanismo cerrado, resaltando en que se debe trabajar aún más en los vínculos mercantiles y en el mercado no sólo de la producción, sino en el mercado del capital, la mano de obra y de los terrenos.

Estos últimos planteamientos orientados desde la perspectiva económica permitieron argumentar en el caso de Piestschmann que las condiciones económicas determinan el desarrollo de esta institución, en tanto se trata de una institución económica más que social (1979, p. 46). En contraparte, los sociólogos intentando dar cuenta de la problemática social latinoamericana de ese momento objetaron que la hacienda no solamente puede verse como un centro económico sino, según Steger, como "un núcleo de creación de ciertas estructuras de poder características en América Latina y para América Latina" (1979, p. 216). Freitag, complementando aquella discusión insistió en que "de esta interpretación los sociólogos podemos deducir un sistema de normas, de valores, de reglas de comportamiento, de roles sociales que a su vez reestructuran una realidad posterior a la económica, una realidad política y social que se explica por tener su base en la hacienda" (1979, p. 221).

Kellenbenz por su parte plantea que es importante reflexionar no tanto en las imágenes que sobre la hacienda "han influido en una medida vastísima en el desarrollo estadual y político de América Latina", (1979, p. 216) sino más bien, cómo la hacienda existía en la realidad, "mientras el literato y el sociólogo piensan en la otra hacienda, cuya imagen repercutió tanto en la vida social y nacional" (1979, p. 122).

Deteniéndonos un momento en el análisis de los ponentes entre las complejas relaciones entre realidad y ficción, o mejor dicho en el papel de la literatura en la construcción de una visión romántica o de protesta social en torno a la hacienda, el debate evidencia aspectos interesantes, como lo advierte Siebenmann, "El hecho que la hacienda acabó siendo para muchos el chivo emisario del atraso económico y social se le debe precisamente a este tipo de literatura, y no a la investigación socio-histórica" (1979, p. 133). Lo que presenta de alguna manera la negatividad con que se enfrenta el mundo de las haciendas en la narración de la crítica social para ese momento.

Lo importante para resaltar de los diversos puntos de vista de esta reflexión en la que se unen otras perspectivas y argumentos del Coloquio de San Gall, no son los aciertos o desaciertos que desde el presente se pueden observar a dichas posturas, se debe destacar más bien, la conclusión que se obtiene al final del debate. Se percibe la hacienda como un sistema económico pero también como un sistema social, que se desarrolla en dinámicas y formas particulares y que hace parte de la realidad social del proceso histórico de América Latina. Debe ser analizada a la luz de la evidencia empírica y las 
diferentes formas como se percibe deben ser contextualizadas en el sistema de representaciones en que se originan.

En los siguientes años hay una gran diversificación de posturas y perspectivas en el trabajo que sobre la hacienda se realiza sobre todo en los centros de investigación de los diferentes países latinoamericanos. Se debe tener en cuenta en este proceso, que en el transcurso de los años setenta y ochenta se advierte una desestabilización del orden social tradicional en América Latina, lo que exteriorizó nuevas percepciones sobre la realidad social. En palabras de Sunkel, se manifestó una cierta desilusión generalizada con los resultados obtenidos de las políticas de desarrollo e industrialización y se promovieron nuevos intentos de cambio desde enfoques distintos (1999, p. 27 -53).

En este contexto, se evidencia un cambio en el protagonismo que había adquirido el estudio de la hacienda como freno histórico del desarrollo latinoamericano. Ante la emergencia de nuevos actores y la percepción de nuevas problemáticas sociales, las ciencias sociales construyeron nuevos objetos de estudio que serían tratados en gran medida por los denominados estudios culturales. Se trató por lo tanto, como lo argumenta Wallerstein (1999) de adelantar en gran medida estudios no eurocéntricos, de resaltar la historia local y relacionar los valores tecnológicos con otro tipo valores. De esta forma, se realizaron principalmente investigaciones sobre género, etnicidad, minorías y en general de diferentes aspectos antes no tratados.

Aunque se percibe un menor interés en el ámbito internacional sobre el estudio de la hacienda, se continuó en diversas escalas algunos acercamientos en el proceso de su investigación. Se trata particularmente de estudios de caso adelantados con nuevas preguntas ante la construcción de nuevas problemáticas sociales. Para esta investigación nos detendremos un momento en el trabajo del historiador sueco Roland Anrup El taita y el toro. En torno a la configuración patriarcal del régimen hacendario cuzqueño publicado en 1990, que nos ilustra el trabajo reciente en torno a la hacienda latinoamericana desde una perspectiva de la historia social y cultural.

En este estudio Anrup pretende explicar las diferentes manifestaciones de los indígenas frente a la reforma agraria en el Perú iniciada a comienzos de 1970. Las diversas actitudes y conductas según el autor, muestran una conexión con el sistema tradicional de la hacienda. Esto plantea la pervivencia y continuidad del régimen hacendario cuzqueño bajo formas renovadas de la dominación tradicional que han dejado huellas síquicas y sociales que continúan produciendo efectos.

Anrup establece de esta forma, que la organización social de la hacienda está determinada por los diferentes grados de disposición de los sujetos que la conforman", por lo tanto, "la forma que asume la hacienda se halla

\footnotetext{
${ }^{1}$ Esta disposición "consiste en un conjunto de operaciones por medio de las cuales una multiplicidad de elementos heterogéneos (fuerzas, recursos, relaciones espaciotemporales, etc.) son investidos de una direccionalidad particular, relacionada con un conjunto de objetivos." Es decir, que los sujetos utilizan diferentes medios y recursos para lograr objetivos y deseos, no siempre con efectos positivos. "“Más que
} 
condicionada por las relaciones de disposición entre el terrateniente y sus trabajadores" (1990, p. 24). Es decir, si bien los trabajadores adscritos a la hacienda, se encuentran sujetos con deberes y derechos legales y contractuales, esto no determina su posición y su función dentro de la configuración social de la hacienda. Existen otra serie de aspectos relacionados con las relaciones de disposición o "lucha por la disposición", lo que caracteriza la forma de la complejidad de la hacienda, que puede variar dentro de una misma hacienda, como en haciendas diferentes. En este sentido el autor la define como:

La hacienda andina en cuanto institución central de la vida rural, se estructura sobre un conjunto de prácticas y relaciones sociales, las que generalmente no le son ni particulares ni específicas y que la conectan en el plano analítico y temporal con instituciones y prácticas que caen fuera de su dominio, que la trascienden. Por lo tanto, la hacienda puede ser tomada como un punto de referencia para un análisis de prácticas distintas, que pueden trascender sus límites y envolver otras instituciones. El régimen hacendario ha determinado formas de gobierno y estructuras políticas, ha influido relaciones sociales más amplias y ha impuesto su tono sobre la cultura en general (1990, p. 26)

Roland Anrup desarrolla así un estudio del sistema hacendario cuzqueño desde el presente a partir de formas de interacción entre lo continuo y discontinuo de las configuraciones pasadas. Lo que evidencia ya, un enfoque y análisis particular en torno a la hacienda latinoamericana como unidad social en el proceso histórico.

\section{II.}

El conocimiento sobre el proceso de transformación de la sociedad y la realidad colombiana se inscribe también en una serie de cambios internos y externos que hicieron posibles nuevas formas de ver y reflexionar desde diferentes perspectivas la sociedad colombiana durante la década de 1960. Por un lado, se hace evidente una cierta preocupación por el desarrollo y modernización del país y por otro lado, emergieron cambios en el panorama cultural y educativo, teniendo como foco central las universidades. Bernardo Tovar (1982, pp. 5 116) argumenta precisamente que la formación de la Nueva Historia de Colombia es un fenómeno universitario relacionado particularmente con la influencia de trabajos extranjeros y la forma de ver la realidad social a partir de la CEPAL (Comisión Económica para América Latina).

En este contexto, los estudios sobre la hacienda tomaron auge principalmente durante los años 70 donde la interdisciplinariedad jugó un papel importante en la investigación. Los adelantos en la relación entre economía, historia y sociología sobre todo, desarrollaron el interés por dar una explicación del subdesarrollo y esclarecer la formación de la estructura económica y social del país, haciendo énfasis en el desarrollo de la estructura agraria. Estos estudios adelantados desde enfoques distintos fueron continuados particularmente en

"poder" y "dominio" tendríamos entonces, sujetos con diferentes grados de disposición, sin que esta disposición esté jamás garantizada.” (Anrup, 1990, p. 23) 
los años 80 y en los siguientes años las publicaciones sobre la hacienda se ven claramente reducidas.

Toda esta serie de investigaciones y publicaciones pueden ser clasificadas en tres categorías según la perspectiva temporal de la hacienda como objeto de estudio: trabajos sobre la hacienda tradicional y su desarrollo durante el periodo colonial y los primeros años de la república caracterizada principalmente por la continuidad de instituciones coloniales como la esclavitud ${ }^{2}$; estudios sobre las haciendas durante el siglo XIX y su inscripción en la dinámica de la economía mundial donde toma relevancia la hacienda cafetera y el fenómeno de la colonización ${ }^{3}$; y los estudios sobre la hacienda durante el siglo XX relacionados sobre todo con las transformaciones agrarias, las luchas campesinas y la violencia entre otros aspectos ${ }^{4}$

Teniendo en cuenta que sería extensivo realizar un recuento histórico de todas las investigaciones para cada una de estas categorías, se presentará el estado de la cuestión de los trabajos que sobre la hacienda se han desarrollado en la primera clasificación, es decir, estudios que han abordado la hacienda tradicional durante el periodo colonial y los primeros años de la república que a partir de la pervivencia de algunas instituciones coloniales presenta una configuración social particular, como es el caso del desarrollo de las haciendas esclavistas. Organización social que se abordará en esta investigación.

Es entonces en la coyuntura de los años 70 cuando los estudios sobre la hacienda adquirieron un protagonismo importante en las ciencias sociales donde aparecen las primeras publicaciones sobre la hacienda tradicional. Una primera muestra del trabajo conjunto entre el análisis de documentos escritos como fuente primaria para la reconstrucción de la hacienda en el marco de la historia socioeconómica lo presentó León Helguera sobre "la hacienda Coconuco" objeto de nuestro estudio. Coconuco: datos y documentos para la historia de una gran hacienda caucana 1823, 1842, 1876 (1980, pp. 189-203), reproduce tres documentos que indican algunos aspectos de las relaciones sociales y económicas que se producen en la hacienda durante tres momentos distintos. Con una breve interpretación Helguera muestra la hacienda Coconuco como un interesante fenómeno caracterizando ciertos rasgos de la vida de los esclavos e indígenas adscritos a la propiedad del Gran General Tomás Cipriano de Mosquera que en años anteriores perteneció a la institución de los expatriados jesuitas.

Un estudio más profundo sobre las haciendas en el periodo colonial lo presentó Germán Colmenares con su trabajo Las haciendas de los jesuitas en la Nueva Granada publicado en 1972. Interesado en el conocimiento de la economía

\footnotetext{
${ }^{2}$ Sobre historiografía colonial véase: Melo, Jorge Orlando. Historiografía colombiana. Realidades y Perspectivas. Editorial Marín Vieco, Medellín, 1996; Tovar Zambrano, Bernardo. "La historiografía colonial", en: La historia al final del milenio. Ensayos de historiografía colombiana y latinoamericana. Volumen I. EUN. Editorial Universidad Nacional, 1994.

${ }^{3}$ Sobre historiografía económica de Colombia véase: Bejarano, Jesús Antonio. Historia económica y desarrollo. La historiografía económica sobre los siglos XIX y XX en Colombia. CEREC, 1994.

${ }^{4}$ Sobre historiografía agraria véase: Bejarano, Jesús Antonio. "Campesinado, luchas agrarias e historia social: Notas para un balance historiográfico", Anuario Colombiano de Historia Social y de la Cultura, Volumen 11, 1983, pp. 251-304.
} 
agrícola colonial el historiador estudia las particularidades de la organización religiosa como empresa económica. En este trabajo se reveló la comercialización de los productos de las haciendas como la actividad económica principal para el soporte de los colegios auspiciados por la institución. Dentro de esta lógica de organización y administración, las haciendas se constituyeron como unidades productivas abiertas orientadas hacia una economía de mercado y al mismo tiempo como unidades productivas cerradas al beneficiarse de una economía doméstica.

Otro avance sobre el conocimiento global de la estructura agraria durante el siglo XVIII, es el trabajo de Hermes Tovar Pinzón Grandes empresas agrícolas y ganaderas. Su desarrollo en el siglo XVIII publicado en 1980. Tovar afirma que si bien el desarrollo agrario fue desigual en el territorio de la Nueva Granada, un nuevo movimiento estimulado por el mercado pareció acelerar el crecimiento en zonas aptas para la expansión de productos referentes principalmente a la ganadería, la caña de azúcar y cacao. Este escenario logró la formación de haciendas denominadas en sentido genérico por el autor como empresas. No obstante, aunque el pensamiento empresario sobre el dinero, la riqueza y la actitud propia del capital haya caracterizado el avance de este proceso en términos de circulación de sus productos, las condiciones del país no favorecieron el desarrollo de la agricultura de exportación como si se impulsó en los otros territorios coloniales.

Por otra parte, Tovar Pinzón señala la remodelación de las fronteras y la expropiación de tierras a los indígenas como aspectos que favorecieron la formación de la gran hacienda, así mismo, cómo la institución de la esclavitud marcó un referente fundamental en el desarrollo de la agricultura durante el siglo XVIII. Sin embargo, el fenómeno del mestizaje, el crecimiento de población libre y mulata, le dio un carácter social más complejo que se evidenció no sólo en su convivencia al interior de ellas, sino también en la rápida transformación y sustitución de la esclavitud por el trabajo libre.

Interesados en el estudio de las dinámicas regionales del territorio de la Nueva Granada, otras investigaciones muestran diversas interpretaciones. Para la Costa Atlántica el trabajo pionero de Orlándo Fals Borda, continúa siendo la referencia básica de consulta sobre el tema. En Capitalismo, hacienda y poblamiento en la Costa Atlántica publicado en 1976 y Mompox y Loba. Historia doble de la Costa publicado en 1980, el autor presenta la hacienda costeña como una institución trascendental que ha logrado sobrevivir en la evolución histórica adaptándose a diversas formas de producción y que ha mostrado una cierta continuidad y preeminencia social y económica de la región. Esta institución, invento del nuevo mundo, inició en la colonia como una relación de explotación y subordinación y ha pasado por diversas etapas hasta llegar a la construcción de relaciones de producción capitalistas. Este proceso de cambio de un sistema señorial que durante los años coloniales presentó relaciones de producción esclavistas sufrió un proceso de transformación con el uso generalizado durante el siglo XVIII de mano de obra libre y servil. Proceso beneficiado también por la expansión territorial de las haciendas y la expropiación de tierras a la población que se conocería posteriormente como campesina. 
Otro aporte de igual importancia lo realizó Adolfo Meisel con su trabajo Esclavitud, mestizaje y haciendas en la provincia de Cartagena: 1533 - 1851. Meisel caracterizó la evolución de la hacienda esclavista en la antigua provincia de Cartagena determinando sus orígenes desde el siglo XVII y el inicio de su decadencia a mediados del siglo XVIII. Distingue en este proceso tres tipos básicos de hacienda: La hacienda ganadera, la hacienda de trapiche y la hacienda de labranza o agrícola. La primera fue la más generalizada en toda la región y la segunda se caracterizó por su mayor inversión tecnológica y el número elevado de esclavos. El fenómeno de crecimiento del mestizaje y el debilitamiento de la esclavitud en la región, permitieron la transición de la hacienda esclavista a la formación de la hacienda feudal en el siglo XVIII sobre la base de la progresiva utilización de mano de obra servil mestiza ${ }^{5}$.

Sobre el conocimiento de las haciendas en la jurisdicción de la provincia de Popayán, los trabajos de Germán Colmenares resultan ser los fundadores. El autor muestra una dinámica propia de la región por la particularidad geográfica y administrativa, además por consolidarse como terreno privilegiado para estudiar el fenómeno de la sociedad esclavista. Su estudio Cali: Terratenientes, mineros y comerciantes. Siglo XVIII publicado en 1975, analiza cómo la actividad minera del Chocó fue el estímulo principal para la formación de las haciendas en el Valle del Cauca. La hacienda definida como un nuevo tipo de latifundio cumplía otro tipo de funciones a diferencia de las grandes propiedades improductivas. Contaba con varias inversiones que consistían en esclavos, ganados, acequias, trapiches, cultivos, las casas de vivienda y en ocasiones con capillas y oratorios. En su interior se generaba un tipo de relaciones particulares en torno a los esclavos, tanto por la rutina general, así como su dieta y relación con el hacendado.

En el segundo tomo de la Historia económica y social publicado en 1979, Colmenares elabora más detalladamente el fenómeno de la esclavitud dentro del sistema de relaciones socioeconómicas. Con la presencia de nuevos colonos que introdujeron nuevos cambios a la sociedad tradicional de terratenientes y encomenderos y un cambio en la organización económica tanto en los yacimientos mineros como en el sector agrícola durante el siglo XVII, el autor advierte la formación de tres tipos de organizaciones agrarias que dependen de la combinación variable de los recursos, es decir, la mano de obra, la propiedad territorial, las técnicas y los mercados (1979, p. 177).

En este sentido distingue el latifundio de frontera dedicado a la explotación extensiva de hatos ganaderos, la hacienda de campo dedicada a la producción de cereales con el uso de mano de obra indígena y la hacienda de trapiche destinada a los sembrados de caña y otros productos con el uso principalmente de mano de obra esclava. Así, las haciendas de trapiche se pueden localizar geográficamente en el valle del río Cauca y las haciendas de campo en la periferia de Popayán.

\footnotetext{
${ }^{5}$ Un avance reciente sobre la hacienda en Valledupar lo presenta Adriana Santos en un pequeño ensayo. Véase: "Haciendas, esclavos y economía en Valledupar entre 1810-1850", en: Colombia y el Caribe. Universidad del Norte, Barranquilla, 2003.
} 
Queda claro según Colmenares, la interrelación de la hacienda con otras unidades productivas, principalmente con la minería y otras haciendas que hicieron posible su sostén y desarrollo. En cuanto a las relaciones sociales, Colmenares crítica a los autores que ven en la hacienda un sistema de benevolencia y no de conflicto. Pues de acuerdo con las prácticas y la coexistencia de varios tipos de explotación de trabajo esclavo en la Gobernación de Popayán, en la haciendas y en el trabajo doméstico se experimentaron rasgos de paternalismo a diferencia de los centros mineros donde se presentaron formas de explotación brutal.

En el artículo comparativo posterior El tránsito a sociedades campesinas de dos sociedades esclavistas en la Nueva Granada: Cartagena-Popayán. 1780 1850 (Colmenares, 1987), Colmenares estudia la hacienda neogranadina como una unidad de agrícola particular en Hispanoamérica, caracterizada principalmente por su carácter subsidiario en un entorno colmado de dificultades de comunicación. En este sentido, "las haciendas esclavistas tenían que cumplir una función apenas subsidiaria del papel militar asignado a Cartagena de Indias, de sus ventajas comerciales entre las cuales sobresalía la trata misma de esclavos, o de la producción aurífera de los distritos mineros dispersos en el interior del país" (1987, p. 7).

Sobre la incorporación de esclavos, Colmenares advierte un contraste entre las dos regiones: en Cartagena fue más temprana y dio lugar al crecimiento de la población esclava en las haciendas, mientras que en la Provincia de Popayán la existencia de grandes cuadrillas en los centros mineros sirvió de estímulo para la creación de haciendas y su sostenimiento ante las crisis del esclavismo. Como rasgo común se puede identificar la formación de tres tipos de hacienda: hato ganadero, hacienda de trapiche y haciendas de labranza. Cada una de ellas condicionadas por diversos factores como el acceso de ciertos productos al mercado, la disponibilidad de mano de obra y la distancia hacia los centros de consumo.

Por otra parte, durante el proceso de transformación social en la primera mitad del siglo XIX, las alternativas con respecto a la mano de obra esclava fueron diferentes en las dos provincias. Ante el crecimiento rápido de la población mestiza, mulata y de negros libres, los grados de dificultad de control del trabajo fueron configurando elementos sociales y culturales autóctonos. Colmenares afirma que "mientras que en Cartagena y en Mompox apenas subsistían unos 1.500 esclavos que alcanzaron la libertad con la ley de 1851, la situación en la antigua provincia de Popayán era muy diferente. En sus haciendas $y$ en sus distritos mineros se encontraba el $60 \%$ de los 16.500 esclavos manumitidos" (1987, p. 5).

Dichos fenómenos se manifestaron en la formación de poblaciones en los márgenes de las haciendas y la constitución de zonas de refugio fuera del sistema tradicional de la hacienda, pero sobre todo, estimularon el crecimiento y el uso masificado de una mano de obra servil evidenciados principalmente en los territorios de Provincia de Cartagena a diferencia de la resistencia y el uso generalizado de cuadrillas de esclavos en las haciendas de la Provincia de 
Popayán, lo que generó además la construcción de diversos tipos de relaciones sociales al interior de ellas.

En los siguientes años dos autores más presentaron nuevos avances sobre la hacienda. Los trabajos de José Escorcia y Zamira Díaz estudiaron la evolución de las haciendas en el desarrollo de los conflictos sociales y las guerras de independencia en la primera mitad del siglo XIX. En el artículo Haciendas y estructura agraria en el Valle del Cauca, 1810-1850 publicado en 1982, Escorcia bosqueja un cuadro detallado sobre las haciendas existentes en el Valle del Cauca señalando la trayectoria de la propiedad y los cambios en el valor de los precios de estas posesiones. Zamira Díaz por su parte publicó Guerra y economía en las haciendas. Popayán, 1780-1830 en 1983. Señaló en este estudio el importante papel de las haciendas al constituirse principalmente como fuente de aprovisionamiento para las tropas, aunque muchas veces como escenarios de enfrentamientos bélicos sufrieron algunos declives en la producción y mercado, "a pesar de los requerimientos bélicos, la estructura agraria sufrió menos transformaciones que en el Valle del Cauca, lo cual ayudó al mantenimiento del mercado local, que conservó un carácter un poco más dinámico que en la otra sección del departamento, si bien de un nivel inferior al del tardío período colonial" (1983, p. 6).

Sigue vigente hasta el momento como estudio de caso y referencia básica sobre la organización económica de una hacienda el artículo de Héctor Llanos Japio: Modelo de hacienda colonial del Valle del Cauca. (S. XVI-XIX) publicado en 1979. La hacienda de Japio propiedad de la familia Arboleda vecina de Popayán, es presentada como un modelo aproximado para el conocimiento de las haciendas del Valle del río Cauca. El autor reconstruye su proceso de evolución y trasformación desde sus orígenes en el siglo XVI y caracteriza aspectos como la producción, el funcionamiento y el trabajo, así mismo describe la transformación espacial y arquitectónica de la hacienda Japio hasta el siglo XIX. ${ }^{6}$

Con otra perspectiva, las aproximaciones a la historia social y cultural colombiana han tomado un nuevo impulso, a partir de investigaciones que se han acercado a la sociedad rural a través de la hacienda durante el régimen esclavista. Por ejemplo, el artículo "La vida cotidiana en las haciendas coloniales" de Pablo Rodríguez y Beatriz Castro (1996), nos introduce a la percepción de los grupos sociales subalternos a partir de una descripción e interpretación de la rutina diaria en la trayectoria histórica de la sociedad colombiana.

\footnotetext{
${ }^{6}$ Existen sin embargo otros acercamientos no publicados productos de trabajos de grado que analizan algunos aspectos de forma superficial y ligera sobre la vida de las haciendas. Véase: Goyes, Víctor Hugo. La hacienda cañera en Cali. Siglo XVIII. Departamento de Historia, Universidad del Valle, 1989; Henao, Ricaurte. Algunos elementos para el estudio de la vida cotidiana en la hacienda "El Alisal", Departamento de Historia, Universidad del Valle, 1992; Balanta, Doris; Mancilla, Neffer. Transformación de la Hacienda en el Gran Cauca "Hacienda Periconegro" - Compañía Agropecuaria de la Bolsa y Periconegro. Departamento de Historia, Universidad del Valle, 1992; Ahumada Escobar, Catalina. Hacienda de Arroyohondo: trayectoria de su propiedad siglos XVI-XX, Departamento de Historia, Universidad del Valle, 2004; Pino, Servio Miguel. Las transformaciones laborales en la hacienda vallecaucana del siglo XIX. Departamento de Historia, Universidad del Valle, 2004.
} 
A partir de esta serie de investigaciones que presentan diversos acercamientos sobre la hacienda como objeto de estudio, es posible señalar que inicia con fuerza y mantiene su predilección en el periodo que va desde los años 70s hasta la década de los $80 \mathrm{~s}$, tiempo relacionado con formas particulares de conocer la realidad social latinoamericana. En los siguientes años el estudio de la hacienda continuó vigente pero bajo otras perspectivas y otros intereses a partir de la creación de nuevos problemas de investigación. En esta dinámica, el congreso Haciendas en la Nueva España y en México Republicano. Viejos y nuevos paradigmas, celebrado en El Colegio de Michoacán en el 2008, coincide en sus planteamientos que después de casi veinte años, se ha renovado una tendencia particular en el estudio sobre el papel de la hacienda en sus diferentes matices en las investigaciones histórico-sociales ${ }^{7}$. En este contexto, las nuevas formas de plantear, abordar e interpretar temas y problemas en torno a la hacienda apenas comienza. "Sin que los problemas estén resueltos, preocupan hoy relaciones entre la sociedad, cultura e historia, entre las prácticas sociales, las representaciones mentales y los factores inconscientes de la cultura, entre el universo simbólico que otorga significación a la experiencia humana y el curso del acontecer histórico" (Tovar, 1994).

\section{Bibliografía}

\section{Libros}

Anrup, Roland. (1990). El taita y el toro. En torno a la configuración patriarcal del régimen hacendario cuzqueño. Estocolmo: Departamento de Historia, Universidad de Gotemburgo. Instituto de Estudios Latinoamericanos, Universidad de Estocolmo.

Barona Becerra, Guido. (1995). La maldición de Midas en una región del mundo colonial: Popayán, 1730-1830. Cali: Editorial Facultad de Humanidades, Universidad del Valle.

Bejarano, Jesús Antonio. (1994). Historia económica y desarrollo. La historiografía económica sobre los siglos XIX y XX en Colombia. Bogotá: CEREC.

Castro Carvajal, Beatriz (Editora). (1996). Historia de la vida cotidiana en Colombia. Bogotá: Grupo Editorial Norma.

Chartier, Roger. (2005). El mundo como representación. Estudios sobre historia cultural. España: Editorial Gedisa.

Chevalier, François. (1999). La formación de las grandes propiedades en México. Tierra y sociedad en los siglos XVI-XVII. México: Fondo de Cultura Económica.

\footnotetext{
${ }^{7}$ Los eventos académicos en torno a la hacienda latinoamericana se realizaron en los años 1975, 1781, 1989 y éste cuarto y último en el año 2008.
} 
Colmenares, Germán. (1970). La Provincia de Tunja en el Nuevo Reino de Granada. Ensayo de historia social. 1839-1800. Bogotá: Universidad de los Andes.

Tercer Mundo Editores.

(1997). Historia Económica y social II. Santa Fe de Bogotá: . (1997). Historia económica y social de Colombia 1537-1719. Santa Fe de Bogotá: Tercer Mundo Editores.

. (1998). Haciendas de los Jesuitas en el Nuevo Reino de Granada. Santa Fe de Bogotá: Tercer Mundo Editores.

Fals Borda, Orlando. (1976). Capitalismo, hacienda y poblamiento en la Costa Atlántica. Bogotá: Editorial Punta de Lanza.

. (1980). Mompox y la Loba. Historia doble de la Costa. Vol. I. Bogotá: Carlos Valencia Editores.

Florescano, Enrique (Coordinador). (1975). Haciendas, latifundios y plantaciones en América Latina. México: siglo XXI.

Freyre, Gilberto. (1933). Casa Grande y Senzala. Formación de la familia brasileña bajo el régimen de economía patriarcal. 2 volúmenes. Argentina: Emecé Editores.

Guillen Martínez, Fernando. (1979). El poder político en Colombia. Bogotá: Editorial Punta de Lanza.

Herrera Ángel, Marta. (2002). Ordenar para controlar. Ordenamiento especial y control político en las llanuras del Caribe $y$ en los Andes Centrales Neogranadinos. Siglo XVIII. Bogotá: Instituto Colombiano de Antropología e Historia, Academia Colombiana de Historia.

Marzahl, Peter G-. (1978). Town in the Empire: Government, Politics, and Society in Seventeenth - Century Popayán. Texas: Institutute of Latin American Studies, The University of Texas at Austin.

. (1979). The Cabildo of Popayán in the seventeenth century; the emergence of a Creole Elite. USA: Universidad de Wisconsin.

Melo, Jorge Orlando. (1996). Historiografía colombiana. Realidades y Perspectivas. Medellín: Editorial Marín Vieco.

Ocampo, Gloria Isabel. (2007). La instauración de la ganadería en el valle del Sinú: la hacienda Marta Magdalena, 1881-1956. Bogotá: Editorial Universidad de Antioquia, Instituto Colombiano de Antropología e Historia, ICANH. 
Siebbenmann, Gustav (Compilador). (1979). La Hacienda en América Latina. Su importancia histórica para la economía y la sociedad. Lateinamerikanisches Instituta an der Hochschule St. Gallen.

Silva, Renán. (2008). Los ilustrados de Nueva Granada 1760-1808. Genealogía de una comunidad de interpretación. Medellín: Fondo Editorial Universidad EAFIT; Banco de la República.

. (2005). República Liberal, intelectuales y cultura popular. Medellín: La Carreta Histórica Editores.

. (2007). A la sombra de Clío. Medellín: La Carreta Histórica

\section{Editores.}

Tovar Zambrano, Bernardo. (1980). Grandes empresas agrícolas y ganaderas. Su desarrollo en el siglo XVIII. Bogotá: Cooperativa de Profesores de la Universidad Nacional de Colombia. Ediciones CIEC.

Verdi Webster, Susan. (2000). Arquitectura y empresa en el Quito colonial: José Jaime Ortiz Alarife Mayor. Quito: Editorial Abya Yala.

Wallerstein, Immanuel (Coordinador). (1999). Abrir las ciencias sociales. Informe de la Comisión Gulbenkian para la reestructuración de las ciencias sociales. México: Siglo veintiuno editores.

\section{Artículos}

Bejarano, Jesús Antonio. (1983). "Campesinado, luchas agrarias e historia social: Notas para un balance historiográfico". En Anuario Colombiano de Historia Social y de la Cultura, Volumen 11, pp. 251-304.

Burrieza Sánchez, Javier. (2004).. "Los ministerios de la Compañía". En Egido, Teófanes (Coordinador). Los jesuitas en España y en el mundo hispánico. (pp. 107-148). España: Fundación Carolina, Centro de Estudios Hispánicos e Ibéricos, Marcial Pons Historia.

Colmenares, Germán. (1983). "Cali: terratenientes, mineros y comerciantes", En Sociedad y economía en el Valle del Cauca. Tomo I.

. (1987). "El tránsito a sociedades campesinas de dos sociedades esclavistas en la nueva granada: Cartagena-Popayán. 1780 - 1850". En Memoria del Primer congreso departamental de Historia, Neiva.

. (1998). "Castas, patrones de poblamiento y conflictos sociales". En Varia, Selección de textos. Selección de textos. Bogotá: TM Editores. pp. 101-142.

Diaz de Zuluaga, Zamira. (1983). "Guerra y economía en las haciendas. Popayán, 1780-1830", Sociedad y Economía en el Valle del Cauca. Tomo II. Bogotá: Biblioteca Banco Popular. 
Escorcia, José. (1982). "Haciendas y estructura agraria en el Valle del Cauca, 1810-1850" En Anuario de Historia Social y de la Cultura. Vol. 10, pp. 119-133.

Helguera, León. (1980). "Coconuco: Datos y documentos para la historia de una gran hacienda caucana". En Anuario Colombiano de Historia Social y de la Cultura. Vol. 10, pp. 189-203.

Jaramillo Uribe, Jaime y Colmenares, Germán. (1984). "Estado, administración y vida política en la sociedad colonial". En Manual de Historia de Colombia, Tomo I. Bogotá: Procultura. pp. 349-414.

Londoño Vega, Patricia. (1994). "Educación femenina en Colombia, 17801880". En Boletín Cultural y Bibliográfico, 31 (37), pp. 21-58.

Llanos Vargas, Héctor. "Japio: Modelo de hacienda colonial del Valle del Cauca. (s. XVI-XIX)”. (1979). En Historia y Espacio. Revista de Estudios históricos regionales. Vol.1, pp. 8-73.

Meisel, Adolfo. (1980). "Esclavitud, mestizaje y haciendas en la provincia de Cartagena: 1533-1851”. En Sociedad y Desarrollo, Vol. 4, pp. 229-277.

Morner, Magnus. (1973). "The Spanish American Hacienda: A survey of Recent Research and Debate". En Hispanic American Historial Review, No. 53, No. 2, pp. 183-216.

Osorio, Laura. (2005). "Los pueblos de indios vinculados con las políticas de separación residencial en el Nuevo Reino de Granada". En Historia Crítica, No. 27. pp. 277-297.

Santos, Adriana. (2003). "Haciendas, esclavos y economía en Valledupar entre 1810-1850". En Colombia y el Caribe. Barranquilla: Universidad del Norte. pp. 61-70.

Silva, Renán. (2009). "Alfabetización, cultura y sociedad. La experiencia del siglo XVIII en el virreinato de Nueva Granada". En Historia Crítica. pp.1-46.

Sunkel, Osvaldo. (1999). "Del desarrollo hacia dentro al desarrollo desde dentro", en: El desarrollo desde dentro. Un enfoque neoestructuralista para América Latina. México: FCE. pp. 27-53.

Tovar Zambrano, Bernardo. (1982). "El pensamiento historiador colombiano sobre la época colonial". En Anuario Colombiano de Historia Social y de la Cultura, Volumen 11. pp. 5-116.

Wolf, Eric; Mintz, Sidney. (1975). "Las haciendas y plantaciones en Mesoamérica y las Antillas". En Florescano, Enrique (coord.). Haciendas, latifundios y plantaciones en América Latina. México: siglo XXI. pp. 493-531. 
Zambrano Pantoja, Fabio. (1982). "Aspectos de la agricultura colombiana a comienzos del siglo XIX". En Anuario de Historia Social y de la Cultura, Vol. 10. pp. $139-190$.

\section{Monografías}

Ahumada Escobar, Catalina. (2004). Hacienda de Arroyohondo: trayectoria de su propiedad siglos XVI-XX'. Tesis de pregrado en Historia. Universidad del Valle, Cali, Colombia.

Balanta, Doris y Mancilla, Neffer. (1992).Transformación de la Hacienda en el Gran Cauca 'Hacienda Periconegro' - Compañía Agropecuaria de la Bolsa y Periconegro. Tesis de pregrado en Historia. Universidad del Valle, Cali, Colombia.

Cleves, Martínez, Camilo Ernesto. (2005). Sobre los trabajadores de la construcción del ferrocarril de Panamá 1850-1855. Tesis de pregrado en Historia. Universidad Nacional de Colombia, Bogotá, Colombia.

Ferreira Esparza, Carmen Adriana. (2001). La economía espiritual entre lo terrenal y lo celestial. Pamplona siglo XVIII. Tesis de pregrado en Historia. Universidad Industrial de Santander, Bucaramanga, Colombia.

Goyes, Víctor Hugo. (1989). La hacienda cañera en Cali. Siglo XVIII. Tesis de pregrado en Historia. Universidad del Valle, Cali, Colombia.

Henao, Ricaurte. (1992). Algunos elementos para el estudio de la vida cotidiana en la hacienda 'El Alisal'. Tesis de pregrado en Historia. Universidad del Valle, Cali, Colombia.

Pino, Servio Miguel. (2004). Las transformaciones laborales en la hacienda vallecaucana del siglo XIX. Tesis de pregrado en Historia. Universidad del Valle, Cali, Colombia.

Recibido: 26 de mayo de 2010.

Aprobado: 18 de noviembre de 2010. 